UNIVERSIDADE DE SÃO PAULO
HOSPITAL DE REABILITAÇÃO DE ANOMALIAS CRANIOFACIAIS

RAYANNE MEYER BARDUZZI

O cuidar do lactente com fissura de lábio e/ou palato associada à síndrome: repercussões psicossociais vivenciadas por pais cuidadores

BAURU

2020 
RAYANNE MEYER BARDUZZI

\section{O cuidar do lactente com fissura de lábio e/ou palato associada à síndrome: repercussões psicossociais vivenciadas por pais cuidadores}

Dissertação apresentada ao Hospital de Reabilitação de Anomalias Craniofaciais Universidade de São Paulo, para obtenção do título de Mestre em Ciências da Reabilitação, na área de concentração: Fissuras Orofaciais e Anomalias Relacionadas

Orientador: Prof. Dr. Armando dos Santos Trettene

(versão corrigida) 
Barduzzi, Rayanne Meyer

O cuidar do lactente com fissura de lábio e/ou palato associada à síndrome: repercussões psicossociais vivenciadas por pais cuidadores/ Rayanne Meyer Barduzzi - Bauru, 2020. 65p.; il.; $31 \mathrm{~cm}$.

Dissertação (mestrado) - Hospital de Reabilitação de Anomalias Craniofaciais, Universidade de São Paulo, 2020.

Orientador: Prof. Dr. Armando dos Santos Trettene

Autorizo, exclusivamente para fins acadêmicos e científicos, a reprodução total ou parcial dessa dissertação, por processos fotocopiadores e outros meios eletrônicos.

Rayanne Meyer Barduzzi

Bauru, 18 de junho de 2020.

Comitê de Ética HRAC-USP

Protocolo $\mathrm{n}^{\mathrm{o}}$ : 3.112 .342

Data: 14/01/2019 
FOLHA DE APROVAÇÃO

\section{Rayanne Meyer Barduzzi}

Dissertação apresentada ao Hospital de Reabilitação de Anomalias Craniofaciais Universidade de São Paulo, para obtenção do título de Mestre em Ciências da Reabilitação.

Área de Concentração: Fissuras Orofaciais e Anomalias Relacionadas

Aprovado em:

\section{Banca Examinadora}

Prof(a). Dr(a):

Instituição:

Prof(a). Dr(a):

Instituição:

Prof(a). Dr(a):

Instituição:

Prof. Dr. Armando dos Santos Trettene Instituição: HRAC-USP

Profa. Dra. Ivy Kiemle Trindade Suedam

Presidente da Comissão de Pós-Graduação do HRAC-USP

Data de depósito da dissertação junto à SPG: 18/06/2020 


\section{DEDICATÓRIA}

Dedico primeiramente a Deus e à Nossa Senhora, que me abençoaram e protegeram durante esta caminhada.

Aos meus pais e irmã, que com muito amor e apoio, não mediram esforços para que eu chegasse até esta etapa de minha vida. Agradeço a eles por sempre me apoiarem e incentivarem na busca constante de crescimento pessoal e profissional; por me fornecerem uma base moral, espiritual e religiosa, a vocês, meu eterno agradecimento;

Ao meu orientador Prof. Dr. Armando dos Santos Trettene, pela oportunidade, paciência e dedicação na orientação deste trabalho. A você, minha eterna admiração e gratidão;

Às amigas e amigos do Hospital de Reabilitação em Anomalias Craniofaciais, pelo apoio e ajuda durante a pesquisa.

Aos cuidadores que participaram dessa pesquisa, por contribuir de forma tão expressiva ao meu crescimento pessoal e profissional. Muito obrigada! 

"O que se opõe ao descuido e ao descaso é o cuidado. Cuidar é mais que um ato; é uma atitude. Portanto, abrange mais que um momento de atenção. Representa uma atitude de ocupação, preocupação, de responsabilização e de envolvimento afetivo com o outro." 



\section{RESUMO}

Barduzzi RM. O cuidar do lactente com fissura de lábio e/ou palato associada à síndrome: repercussões psicossociais vivenciadas por pais cuidadores [dissertação]. Bauru, SP: Hospital de Reabilitação de Anomalias Craniofaciais, Universidade de São Paulo; 2020.

Objetivo: compreender as implicações psicossociais vivenciadas por pais cuidadores decorrentes do cuidado do filho com fissura de lábio e/ou palato associado às síndromes. Método: estudo qualitativo desenvolvido em um hospital público e terciário, situado no interior de São Paulo, Brasil. Foram incluídos cuidadores informais de lactentes com fissura de lábio e/ou palato associados às síndromes que acompanhavam seus filhos durante a internação na Unidade de Cuidado Semi-intensivo. A amostra intencional foi definida por saturação teórica e constou de 16 participantes. Para a coleta de dados, utilizou-se a entrevista semiestruturada que foi audiogravada, e posteriormente transcrita na íntegra; a qual foi realizada em ambiente privativo e individualmente. Os questionamentos foram: como tem sido para você cuidar de seu filho? Quais foram as principais mudanças em suas atividades diárias depois que começou a cuidar de seu filho? Como referencial metodológico, utilizou-se a Análise de Conteúdo Temática e como referencial teórico, o Interacionismo Simbólico. Resultados: a partir das análises dos conteúdos, elencaram-se cinco categorias referentes às repercussões psicossociais, sendo: implicações diante do diagnóstico e início do tratamento; implicações relacionadas às questões financeiras e de atividades remuneradas; implicações relacionadas à rede de apoio familiar; implicações relacionadas ao processo de cuidar e saúde do cuidador; implicações referentes ao acesso aos recursos de saúde. Considerações finais: as implicações psicossociais vivenciadas por esses cuidadores são multifacetadas e complexas. Conhecê-las, viabiliza o planejamento e a implementação de ações que contribuam, além do processo reabilitador das crianças, para a saúde e qualidade de vida daqueles que cuidam.

Descritores: Fenda labial. Fissura palatina. Anormalidades craniofaciais. Cuidadores. Sistemas de apoio psicossocial. Impacto psicossocial. 



\begin{abstract}
Barduzzi RM. Caring for infants with cleft lip and / or palate associated with the syndromes: psychosocial repercussions experienced by caregiving parents [dissertation]. Bauru, SP: Hospital for Rehabilitation of Craniofacial Anomalies, University of São Paulo; 2020.

Objective: to understand the psychosocial implications experienced by caregiving parents resulting from the care of the child with cleft lip and / or palate associated with the syndromes. Method: qualitative study developed in a public and tertiary hospital, located in the interior of São Paulo, Brazil. Informal caregivers of infants with cleft lip and / or palate associated with syndromes that accompanied their children during hospitalization in the Semiintensive Care Unit, were included. The intentional sample was defined by theoretical saturation and consisted of 16 participants. The semi-structured interview was applied for data collection, which was audio recorded and then fully transcribed; which took place in a private and individual environment. The questions were: How do you feel taking care of your child? What were the main changes in your daily activities after you started taking care of your child? The Thematic Content Analysis was applied as a methodological framework and Symbolic Interactionism was used as a theoretical framework. Results: based on the content analysis, five categories were listed regarding the psychosocial repercussions, namely: implications for the diagnosis and the beginning of treatment; implications related to financial matters and paid activities; implications related to the family support network; implications related to the caregiver's health and care process; implications regarding access to health resources. Final considerations: the psychosocial implications experienced by these caregivers are multifaceted and complex. Acknowledging them enables planning and implementation of actions which contribute, in addition to the children's rehabilitation process, to the health and quality of life of the caregivers
\end{abstract}

Keywords: Cleft lip. Cleft palate. Craniofacial Abnormalities. Caregivers. Psychosocial Support Systems. Psychosocial Impact. 



\section{SUMÁRIO}

1 INTRODUÇÃO

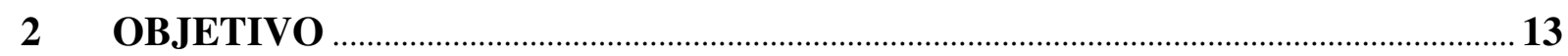

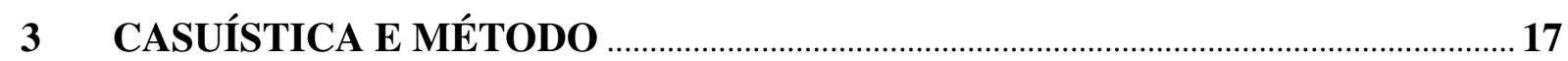

3.1 DELINEAMENTO DO ESTUDO_......................................................................................... 19

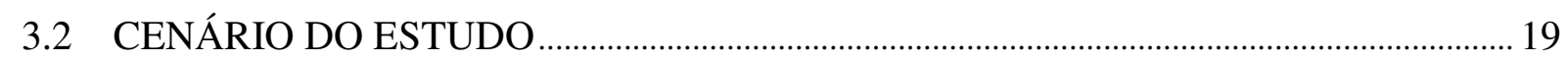

3.3 AMOSTRAGEM, CRITÉRIO DE INCLUSÃO E EXCLUSÃO ……………................... 19

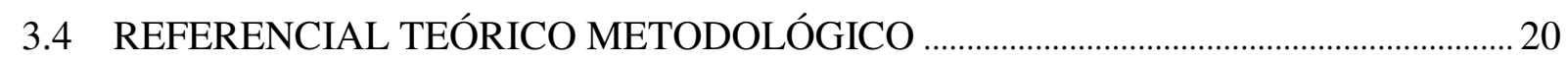

3.5 COLETA DE DADOS ………………………………………………………………. 20

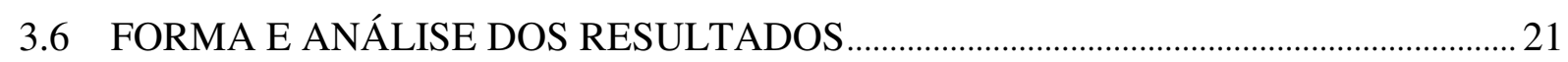

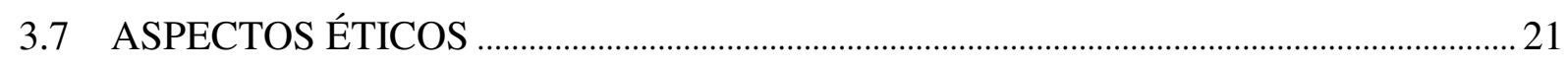

4 RESULTADOS

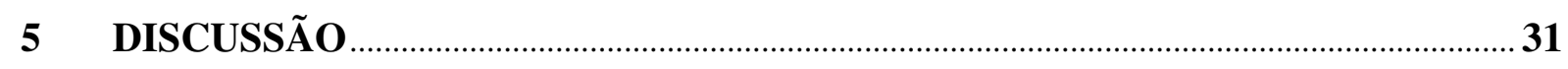

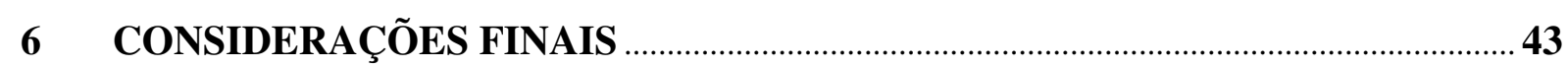

REFERÊNCIAS .

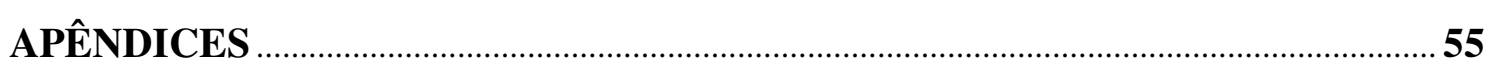

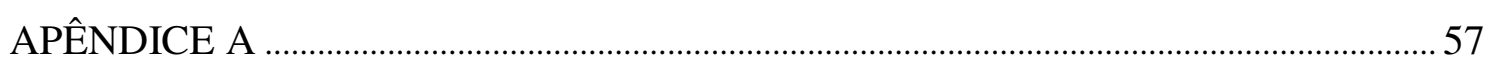

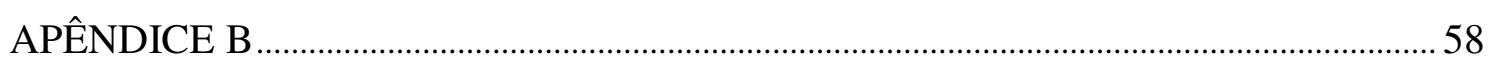

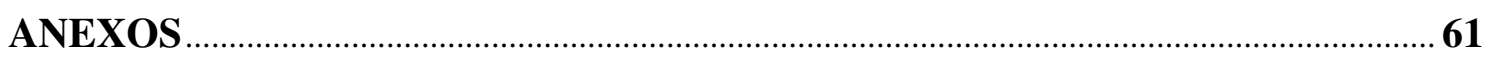






\section{INTRODUÇÃO}

A fissura de lábio e/ou palato apresenta-se como demanda de saúde pública, pois está entre as malformações mais comuns entre as que acometem a face. No Brasil, a incidência é de 1/750 nascidos vivos. A etiologia relaciona-se à interação complexa entre exposições ambientais, fatores genéticos e epigenéticos, podendo apresentar-se isoladamente ou em associação às síndromes (FREITAS et al., 2012; XIAO et al., 2017).

As variações morfológicas nas fissuras de lábio e/ou palato são inúmeras, gerando problemas de ordem funcional, estética e psicossocial, exigindo tratamento especializado e interdisciplinar. Estima-se que cerca de $30 \%$ a $50 \%$ dos pacientes com fissura apresentam outras malformações ou síndromes associadas. Nesses casos em especial, os problemas de ordem funcional apresentam-se com maior intensidade, afetando principalmente a respiração e a alimentação, exigindo a internação do bebê logo após o nascimento, ou em seu primeiro mês de vida (FREITAS et al., 2012).

Dentre as síndromes associadas às fissuras de lábio e/ou palato, prevalecem a Sequência de Robin, Stikcler, Treacher Collins, Apert, Crouzon e Moebius (SALMEN; MARQUES, 2015). Com frequência essas crianças necessitam de suporte respiratório e/ou alimentar, incluindo cânulas nasofaríngeas, traqueostomia, sondas alimentadoras, gastrostomia, tratamento postural antirrefluxo, entre outros. Contudo, o uso dessas terapias, na grande maioria dos casos, não contraindica a alta hospitalar, desde que seus pais ou cuidadores informais sejam treinados para a manutenção dos cuidados no domicílio (MONDINI et al., 2018).

Assim, frente a essa nova demanda de cuidados e responsabilidades, esses cuidadores vivenciam mudanças significativas em suas vidas, tendo que se adaptar à nova realidade a eles imposta. Nesse sentido, com frequência, os pais assumem a responsabilidade pelo cuidado dos filhos, cumprindo o ofício de cuidadores informais (RAZERA et al., 2017; BANHARA et al., 2020).

Esses pais cuidadores, além de enfrentar as dificuldades relacionadas ao processo de cuidar do bebê, terão que lidar com sentimentos e situações conflitantes e estressoras, incluindo o medo, culpa e o luto, que se fazem presentes desde o momento do diagnóstico de seus filhos, seja durante a gravidez ou no parto, podendo se estender até a infância, adolescência ou vida adulta (NIDEY et al., 2016). 
Em suma, o processo de cuidar configura-se como tarefa árdua, podendo acarretar sobrecarga a quem cuida, além de desordens físicas, psicológicas, emocionais, sociais e financeiras, com necessidade de reorganização familiar (CARVALHO; ARAÚJO; VERÍSSIMO, 2019).

Frente ao exposto, buscou-se responder a seguinte pergunta: quais são as implicações psicossociais vivenciadas por pais cuidadores informais de lactentes com fissura de lábio e/ou palato associadas às síndromes?

Embora estudos sobre os cuidados ao lactente com fissura de lábio e/ou palato associados às síndromes estejam disponíveis, aqueles referentes ao universo das implicações sociais vivenciadas por pais cuidadores, são incipientes. Ainda, deve-se considerar que o sucesso do processo reabilitador e a qualidade dos cuidados prestados dependem muito da saúde física, emocional e psicossocial dos cuidadores. Esses fatores justificam a realização deste estudo. 



\section{OBJETIVO}

Compreender as implicações psicossociais vivenciadas por pais cuidadores decorrentes do cuidado do filho com fissura de lábio e/ou palato associados às síndromes. 



\section{CaSuística e Método}





\section{CASUÍSTICA E MÉTODO}

\subsection{DELINEAMENTO DO ESTUDO}

Trata-se de em estudo descritivo, transversal, de enfoque qualitativo. A pesquisa qualitativa busca trabalhar com o universo de significados, motivos, crenças e valores, como parte da realidade social dos indivíduos (MINAYO, 2013).

Este estudo norteou-se pelos Critérios Consolidados para Relatos de Pesquisa Qualitativa - COREQ, que consiste em um checklist de 32 itens para relatar entrevistas ou grupos focais, sendo os métodos mais comuns entre os utilizados para a coleta de dados na pesquisa qualitativa em saúde. Os critérios incluídos no checklist auxiliam os pesquisadores a relatar aspectos importantes da equipe de pesquisa, métodos e contexto do estudo, resultados, análise e interpretações (TONG; SAINSBURY; CRAIG, 2007).

\subsection{CENÁRIO DO ESTUDO}

A presente investigação foi desenvolvida em um hospital público, terciário, de referência no atendimento de pacientes com anomalias craniofaciais e síndromes relacionadas, situado no interior de São Paulo, Brasil. Possui 91 leitos e é gerido com recursos da Universidade de São Paulo e do Sistema Único de Saúde.

A unidade hospitalar de Cuidado Semi-intensivo foi contemplada neste estudo. É composta por oito leitos destinados ao atendimento de recém-nascidos até crianças com dois anos de idade completos, que frequentemente apresentam demandas respiratórias e alimentares. Além disso, os cuidadores informais permanecem durante a internação das crianças para receberem treinamento quanto aos cuidados, visando sua manutenção no domicílio após a alta hospitalar.

\subsection{AMOSTRAGEM, CRITÉRIOS DE INCLUSÃO E EXCLUSÃO}

A amostra intencional e por conveniência foi definida por saturação teórica, que aconteceu na $16^{\mathrm{a}}$ entrevista, ou seja; participaram 16 cuidadores informais. A determinação da amostra por saturação teórica é operacionalmente definida como a suspensão da inclusão de novos participantes, quando os dados obtidos passam a apresentar, na avaliação do 
pesquisador, certa redundância ou repetição, não sendo considerado relevante persistir na coleta de dados (FONTANELLA; RICAS; TURATO, 2017).

Os critérios de inclusão compreenderam: ser pai, mãe ou cuidador informal responsável, de lactentes internados na Unidade Semi-intensiva no período da coleta de dados, que não estivessem na primeira internação, configurando o cuidado no domicílio.

\subsection{REFERENCIAL TEÓRICO METODOLÓGICO}

Como referencial teórico utilizou-se o Interacionismo Simbólico, onde a definição da situação vivenciada é central para direcionar a ação, uma vez que são causadas por um processo ativo de tomada de decisão pelo indivíduo, além da interação consigo mesmo e com os outros. Compreende cinco ideias centrais, incluindo: o papel da interação social, do pensamento, da definição, do presente e do ser humano ativo. Em suma, a partir do estabelecimento de significados, ocorre a ação. Assim, o indivíduo na medida em que interage, sua vivência atual influencia suas ações. Neste sentido, todo fenômeno precisa ser apreendido e compreendido da perspectiva daquele que o vive (CHARON, 2010).

Como referencial metodológico, utilizou-se a Análise de Conteúdo Temática, que segundo Bardin (2013) consiste em uma técnica de análise de discursos, visando compreendêlos, sendo subtraídos temas, categorias e subcategorias, ou seja; a possibilidade descobrir os núcleos de sentido que compõem uma comunicação.

\subsection{COLETA DE DADOS}

Para a coleta de dados, utilizou-se a entrevista estruturada com as seguintes perguntas: Como tem sido para você cuidar de seu filho? Quais foram as principais mudanças em suas atividades diárias depois que começou a cuidar de seu filho? Quais são as suas maiores dificuldades em cuidar de seu filho? Você se sente apoiado? Você conseguiu acessar os recursos comunitários (Tratamento Fora do Domicílio - TFD/Posto de Saúde/Carona Amiga/Benefício de Prestação Continuada - BPC), para manutenção e continuidade do tratamento?

Previamente, a pesquisadora principal teve acesso ao agendamento dos pacientes, por meio do qual, foi possível eleger os possíveis participantes da pesquisa. Feito isto, após a 
internação, os cuidadores informais foram convidados a participar da pesquisa, sendo esclarecidos os objetivos e a forma de coleta de dados.

As entrevistas ocorreram em ambiente privativo, durante a internação dos lactentes, em horários pertinentes aos pais, e foram gravadas em aparelho de áudio digital. Após cada entrevista transcreveu-se o conteúdo das gravações na íntegra, visando facilitar o processo de análise dos dados emergentes.

O tempo médio de duração das entrevistas foi de 40 minutos. A análise dos dados aconteceu concomitantemente à realização das entrevistas visando identificar quando as falas se tornaram recorrentes.

Ainda, os participantes foram caracterizados segundo a idade, sexo, estado civil, número de filhos, escolaridade e classificação socioeconômica, utilizando-se um instrumento confeccionado pelos autores para tal (APÊNDICE A).

As informações quanto a idade, sexo, estado civil, número de filhos e escolaridade foram obtidas durante a entrevista, enquanto a classificação socioeconômica foi obtida por meio de consulta ao prontuário no campo do Serviço Social. Para a classificação socioeconômica, utilizou-se a padronizada na Instituição, que foi proposta por Graciano et al. (2015).

A coleta de dados ocorreu entre janeiro a maio de 2019.

\subsection{FORMA E ANÁLISE DOS RESULTADOS}

O tratamento dos resultados realizou-se pela inferência e interpretação dos conteúdos por categorias e similaridade, seguindo a metodologia da Análise de Conteúdo Temática, sistematizada nas seguintes fases: pré-análise - através da leitura flutuante dos conteúdos das entrevistas, por meio dos princípios da exaustividade, representatividade, homogeneidade e pertinência; exploração do material - onde construíram-se as operações de codificação por meio da identificação de palavras-chaves e temas correlatos, com posterior agregação das informações em categorias temáticas; interpretação - tratamento dos resultados, inferência e interpretação, respaldados no referencial teórico do Interacionismo Simbólico (BARDIN, 2013; CHARON, 2010). 
Analisando as narrativas, uma a uma, interpretou-se o que cada participante fazia da sua experiência em cuidar do filho com fissura de lábio e/ou palato associados às síndromes. Com a releitura exaustiva das transcrições, foi possível delinear sentimentos, vivências incomuns às famílias, embora cada experiência fosse única. Por conseguinte, as narrativas foram agrupadas de acordo com a semelhança de momentos, sentimentos e/ou ações. A partir desses temas emergiram subtemas que revelaram a experiência dos pais cuidadores.

\subsection{ASPECTOS ÉTICOS}

A pesquisa iniciou-se após a aprovação do Comitê de Ética em Pesquisa do Hospital, cenário desta pesquisa, que se deu por meio do ofício 3.112.342 de 14/01/2019 e CAAE: 04319418.0.0000.5441 (ANEXO A). Os participantes formalizaram a participação neste estudo por meio da assinatura do Termo de Consentimento Livre e Esclarecido (APÊNDICE B). Para identificar as falas e garantir o anonimato, utilizou-se a letra "C" de Cuidador para cada participante, bem como números arábicos sequenciais. 


\section{RESULTADOS}





\section{RESULTADOS}

Participaram deste estudo 16 cuidadoras informais, todos do sexo feminino, com média de 31 anos de idade (DP=6.9), sendo 14 (87,5\%) mães, uma tia e uma avó materna. Dessas, prevaleceram as que possuíam ensino médio completo (44\%), casadas (62\%), com 2 filhos, desempregadas (55\%) e pertencentes à classificação social baixa (63\%).

A partir da análise dos conteúdos, elencaram-se quatro categorias referentes às repercussões psicossociais relacionadas ao processo de cuidar, sendo: (1) implicações diante do diagnóstico e início do tratamento, (2) implicações relacionadas às questões financeiras e de atividades remuneradas, (3) implicações relacionadas ao processo de cuidar e (4) implicações referentes ao acesso e recursos de saúde, conforme ilustrado na Figura 1.

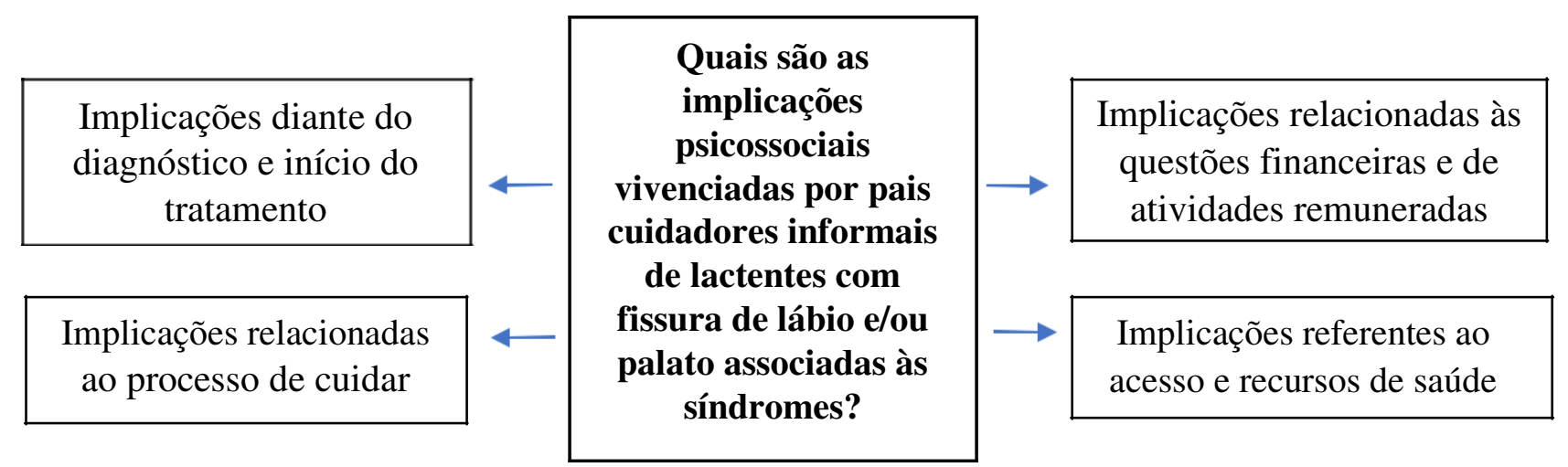

Figura 1. Categorias referentes as implicações psicossociais vivenciadas por pais cuidadores informais de lactentes com fissura de lábio e/ou palato associadas às síndromes. Bauru, SP, 2020.

A categoria "implicações diante do diagnóstico e início do tratamento", caracterizou-se por falta de acesso às informações e uma gama variada de sentimentos, incluindo: susto, insegurança, medo e preocupação.

“O diagnóstico assustou muito a gente, eles já sabiam que ele tinha fissura e era Pierre Robin. Uma insegurança total. Procurei informações na internet, pois eles não falavam sobre os cuidados $[\ldots] "$ C 16

"No começo foi bem difícil, eu achava que não conseguiria fazer todas as coisas que me ensinavam, [...] estava bastante assustada e tinha medo até de dar banho nela [...]" C 5 
"Foi tudo muito tenso [...] no começo eu achei que fosse só a fissura, não sabia que ela tinha Sequência de Robin. Pensei em como ela ia se alimentar. Ninguém me dava informação" C 13

Outra categoria desvelada a partir dos discursos foi "implicações relacionadas às questões financeiras e de atividades remuneradas". As cuidadoras relataram dificuldades referentes à permanência no trabalho frente às necessidades de cuidados que o lactente demandava. Ressalta-se que o tratamento para lactentes com fissura de lábio e/ou palato associado às síndromes, exige do cuidador retornos periódicos para tratamento especializado, demandando muito tempo daqueles que cuidam.

"A gente não consegue fazer mais nada, só cuida dela [...] Eu trabalhava, peguei licença maternidade, peguei férias e agora vou tentar me afastar pelo INSS porque ela tem muito retorno. Voltar ao trabalho por enquanto não vai dar [...]." C 5

"Eu trabalhava, agora estou de férias, mas a empresa vai me demitir porque eles têm consciência que eu tenho um filho fissurado e com síndrome. Fico levando atestado, e para empresa não compensa" C 9

"Eu trabalhava, mas pedi demissão para cuidar dela [...] agora ela que precisa mais da minha atenção." C13

Além dos retornos periódicos ao hospital, o cuidador também se depara com a necessidade de cuidados específicos do lactente, resultando diretamente na necessidade de ausentar-se do trabalho e desenvolver a função social de cuidar.

"Eu era manicure antes, agora eu não trabalho mais [...] e era uma coisa que eu gostava de fazer. Não tem como pegar uma coisa para fazer, a gente pega a criança, passa remédio, passa leite, passa o leite de novo e assim vai. Não tem como trabalhar..." C 2

"Eu larguei tudo, o trabalho, a faculdade. Antes eu trabalhava, pedi demissão [...] eles até falaram: não faz isso, arruma alguém para ficar com ela, mas era só eu e eu... aí eu larguei tudo [...]" C 6

Outra categoria que emergiu, referiu-se às "implicações relacionadas ao processo de cuidar", onde foram observadas as dificuldades referentes aos aspectos subjetivos e objetivos do cuidado, sendo que a grande maioria referiu ter experimentado, em algum momento, elevado nível de estresse e sobrecarga relacionados ao ônus imposto pelo cuidar do lactante, além da maternidade, acrescido dos cuidados com a casa, outros filhos e com o cônjuge. 
"Eu me sinto sobrecarregada! Não tenho ajuda de ninguém e fica difícil lidar com ela e as tarefas da casa; a gente dá conta, mas do jeito da gente [...] minha prioridade é ela! Cansa, não sobre nenhum tempo; quando pensa em dormir ou descansar, ela acorda e começa tudo de novo $[\ldots] "$ C 10

"Depois que recebe alta é aquela coisa; se ele deixar, você come... se deixar, você toma banho... a gente vive em prol dele agora [...].” C 2

"Eu me sinto sobrecarregada, e olha que eu não tenho outros filhos; mas a gente não tem só ela pra cuidar; tem a casa, tem o marido, tem que correr atrás das coisas dela... e tudo sou eu que faço, porque meu marido trabalha." C10

A sobrecarga e o estresse se relacionaram principalmente ao fato das mães assumirem como protagonistas o cuidado do lactente; seja por não receberem apoio do cônjuge ou dos familiares; seja por não confiarem nos cuidados prestados por outras pessoas. Ainda, desvelou-se que o estigma social da fissura de lábio e/ou palato associado às síndromes, encontra-se explícito também no seio familiar.

"Quem me ajuda é a minha filha, mas ela não administra a dieta nem cuida da traqueostomia. Para isso só sou eu mesmo, mas só dela estar ali por perto de mim já é uma grande coisa [...] meu esposo me ajuda, mas na hora de cuidar da traqueostomia e da sonda ele tem medo e sai de perto [...]" C 7

"Quem está aqui (hospital), com ela sou eu... e quem sabe mais cuidar dela, sou eu! Então em casa sou eu que cuido dela; a avó me ajuda, mas com o irmão dela... eu até ensinei ela dar a mamadeira, mas ela prefere cuidar do outro." C13

"É tudo eu; ninguém quer ficar com ele, então todo lugar que eu tenho que ir, levo ele [...]" C11

“A gente não consegue fazer mais nada, só cuida dela mesmo [...] a única pessoa que não tem medo de cuidar dele é a minha irmã, mas ela trabalha, então não tem como ajudar muito [...]” C5

Outra dificuldade desvelada, referiu-se à mudança no relacionamento com os outros filhos, que se associou à falta de tempo dos pais devido à necessidade de maior atenção à criança mais vulnerável. 
"Minha maior dificuldade é dividir a atenção sem sobrecarregar meu outro filho; me programo para ficar com ele e não consigo [...]" C9

"Eu tenho um menino de seis anos e ele é bem carinhoso... mas é bem cansativo. Quando eles dormem, eu aproveito para fazer o serviço de casa; mas a minha preocupação maior é meu outro filho; às vezes ele quer mais atenção... ele pede atenção e eu não posso [...] C4

O ambiente familiar é de suma importância no contexto de reabilitação do lactante e seu cuidador, pois a percepção e o enfrentamento desse processo são influenciados por expectativas, atitudes e apoio da família. Assim, quando o meio familiar consegue se organizar de forma a contribuir com o cuidado, oferecendo tranquilidade e suporte, torna-se um facilitador desse processo.

"Quando preciso vir para cá (hospital), minha família me ajuda; minha sogra vai para minha casa e cuida do meu outro filho, e eu fico mais tranquila" $[\ldots] \mathrm{C} 4$

Outro aspecto importante no cotidiano do cuidador relacionou-se com a necessidade de acionar e acessar os direitos disponibilizados pelo Sistema Único de Saúde (SUS), categoria que elencamos como "implicações referentes ao acesso dos recursos de saúde". Ainda, apreenderam-se questões denominadas como facilitadoras, incluindo o acesso ao tratamento especializado e o olhar humanizado da equipe.

"Quando cheguei aqui (hospital), foi tudo ótimo. A cânula que colocaram nela foi a melhor coisa que aconteceu na vida dela, porque respirou melhor e conseguiu comer melhor [...]" C13

"Quando eu cheguei aqui (hospital), tudo ficou mais tranquilo, porque eles conhecem os casos e me explicaram e treinaram muito bem. Fui para casa segura" C 12

"Se eu estivesse em outro hospital eu não sei como teria sido, porque aqui o pessoal ensina, tranquiliza, e não deixam você ir embora sem ter a segurança de fazer os cuidados" C 5

“Aqui (hospital), eles só te dão alta quando veem que você (mãe), aprendeu cuidar, e a criança está bem para ir para a casa... é um diferencial!” C 13

Contudo, para conseguir acesso ao tratamento especializado, os cuidadores enfrentaram barreiras significativas de acesso, na garantia do transporte ou no encaminhamento efetivo ao serviço especializado. 
"Quando a gente conseguiu a transferência para cá, eu entrei judicialmente para conseguir o transporte aéreo, porque não tínhamos condições de pagar" C 6

"Ajuda de custo eu nunca recebi. A passagem aérea, quando ele nasceu, eu precisei ir à televisão, chamar a reportagem... aí eles liberaram e consegui vir; mas da segunda vez, nós perdemos a consulta aqui (hospital), porque eles não liberaram as passagens... eu entrei na justiça para conseguir as passagens." C 11

"Quando ela foi avaliada, fiquei sabendo que era Robin, e que tinha que vir pra cá (hospital), urgente. Chegou aqui com dois meses e perdeu muito peso no começo [...]" C 14

"Ele ficou muito mal e não conseguia respirar; aí disseram que a gente precisava vir para cá (hospital); chegamos quando ele já tinha 45 dias” C15

O lactente com fissura de lábio e/ou palato associado às síndromes, necessita, além do tratamento especializado, de insumos e fórmulas especiais, cuja garantia de acesso e aquisição foram consideradas como difíceis.

"O leite... demorei três meses pra conseguir; os outros materiais, como os equipos, estão sendo muito difícil. Tem que ficar correndo atrás e implorando.” C 2

"Eu consegui o leite e os materiais, mas com muito trabalho [...] a gente tem que ficar brigando pra conseguir os materiais [...] a sonda é o mais difícil e muitas vezes temos que comprar." C3

“Até agora não me deram nada e, como não me deram, eu comprei, por que não posso deixar o bebê sem se alimentar; a sonda de aspirar forneceram um pouco, e disseram que tinha que esperar chegar; não posso deixar de aspirar, então tenho que dar um jeito e comprar [...]" C 7

"Eu consegui o leite, mas foi difícil, muita burocracia... o leite e os insumos, foi muito trabalhoso; meu marido precisou sair do trabalho dele e ficar indo lá (SMS), senão eles não davam... foram muitos dias [...]" C 10 


\section{DISCUSSÃo}





\section{DISCUSSÃO}

\section{IMPLICAÇÕES DIANTE DO DIAGNÓSTICO E INÍCIO DO TRATAMENTO}

$\mathrm{Na}$ categoria "implicações diante do diagnóstico e início do tratamento", evidenciou-se que os pais cuidadores apresentavam medo e insegurança diante da nova rotina de cuidados que o lactente demandava. Contudo, não hesitaram em acolher e cuidar do filho.

A espera de um bebê gera grande expectativa nos pais e na família. De fato, os pais ao terem conhecimento da malformação, experimentam sentimentos negativos, como o medo frente ao desconhecido, além de mudanças bruscas em suas atividades rotineiras. Vivenciam o diagnóstico como uma sentença para a criança e para a família, sentindo-se frágeis e temerosos frente às possíveis dificuldades que enfrentarão. Inicialmente, a preocupação centraliza-se nos aspectos voltados ao cuidado da criança, e a preocupação quanto à sobrevivência. Posteriormente, surgem preocupações com a questão estética (BOLLA et al., 2013).

A partir da interação humana, os que participam dela se veem obrigados a inibir tendências, dirigindo-as à ação propriamente dita. Assim, inclinações, impulsos, desejos e sentimentos podem ser refreados, em razão daquele que se considera a partir do julgamento ou interpretação, orientando suas ações e reconsiderando sua conduta. As pessoas ao se defrontarem com distintas situações da vida, são capazes de modelarem seus significados (CHARON, 2010).

De fato, o nascimento uma criança com malformação, sempre temido e nunca esperado, exerce impacto emocional significativo em todos os membros da família, que veem assim a sua rotina profundamente afetada. Neste momento, os pais necessitam receber informações sobre a anomalia e sobre o processo reabilitador (SMITH; CHEATER; BEKKER, 2015).

O diagnóstico da fissura de lábio e/ou palato, pode ser um fator estressante, já que os pais se preocupam com os resultados inesperados das transições previstas do ciclo de vida, podendo assim aumentar a pressão sobre o sistema familiar e influenciar na capacidade dos pais de se adaptarem a essa nova situação (O'HANLON; CAMIC; SHEARER, 2012).

Nesse contexto, os sentimentos vivenciados incluem a preocupação, ansiedade, surpresa, choque e tristeza (LUQUETTI et al, 2018; HLONGWA; RISPEL, 2018; VIANA et al., 2019), conforme evidenciado neste estudo. 
Ainda, o diagnóstico da malformação gera reações de negação da doença, além de questionamentos sobre o merecimento de ter esse filho; rejeição quanto à condição da criança e perda do sonho do filho perfeito idealizado (LUQUETTI et al, 2018). Não obstante, a família vivencia momentos de inquietude por desconhecer os cuidados especiais de que a criança necessitará (LIMA; SALES; SERAFIM, 2019).

A insegurança frente ao diagnóstico e aos cuidados necessários também se relaciona à falta do acesso às informações pertinentes, gerando grandes expectativas no cuidador, que por vezes não são sanadas de imediato. A espera pelo tratamento especializado e respostas às demandas emergentes do bebê, evidenciadas neste estudo, ratificam a importância do acesso e participação dos cuidadores na aquisição do conhecimento, sendo essa uma das maiores necessidades referidas, uma vez que ter o conhecimento, culmina em melhor percepção do novo papel que exercerão, visando desenvolvê-lo de forma independente (FERNANDES; ANGELO, 2016).

Evidenciou-se a partir dos discursos, as dificuldades referentes ao diagnóstico da Sequência de Robin, que se apresenta como uma tríade de anomalias, caracterizada por micrognatia (região mandibular retroposicionada), glossoptose (queda da base da língua) e fissura de palato, sendo essa última presente na grande maioria dos casos. A sintomatologia inclui a obstrução das vias aéreas e dificuldades alimentares, sendo mais frequentes e graves no período neonatal, representando a maioria das internações (SALMEN; MARQUES, 2015).

Em síntese, ter um filho com fissura de lábio e/ou palato, associado as síndromes atribui à família, além de toda repercussão do diagnóstico, uma nova função; de ser cuidador. Com isso, o temor e a insegurança aumentam, pois a família não se sente preparada para desempenhar essa função.

$\mathrm{Na}$ área da saúde, entende-se como cuidador informal, aquele que vivência o ato de cuidar sem ter formação técnico-científica para tal, responsabilizando-se em desenvolver ações de ajuda, proteção, prevenção e recuperação da saúde, em situações nas quais a pessoa cuidada não possa realizar com autonomia (CÂMARA et al., 2016).

Em outras palavras, ao defrontar-se com distintas situações da vida, os significados se manipulam e se modificam, mediante um processo interpretativo desenvolvido pela pessoa, neste caso, os cuidadores (CHARON, 2010). 


\section{IMPLICAÇÕES RELACIONADAS ÀS QUESTÕES FINANCEIRAS E DE ATIVIDADES REMUNERADAS}

Dentre os impactos vivenciados por cuidadores informais nas atividades de vida diária, destacam-se os financeiros e sociais (EMEKA et al., 2017; BELUCI et al., 2019), corroborando aos achados apresentados na categoria "implicações relacionadas às questões financeiras e de atividades remuneradas", onde as cuidadoras pontuaram a necessidade de abandonar o trabalho, devido`as necessidades de cuidados do lactante, culminando muitas vezes em não atendimento das demandas materiais, necessárias para a sobrevivência da família (HLONGWA; RISPEL, 2018).

Frente à nova realidade, nos tornamos objetos sociais uns para outros, por meio de símbolos a favor das prioridades, onde nossas ações resultam em tomada de decisões, que culminam em assumirmos e desempenharmos papéis (CHARON, 2010).

Além da preocupação dos cuidadores com a saúde e a qualidade de vida de seus filhos, os mesmos se depararam com a necessidade de deixarem de exercer atividades remuneradas. Soma-se a isso, o aumento dos encargos financeiros advindos do tratamento e da nova rotina, como custos da busca e permanência em centros de reabilitação, normalmente distantes de suas residências (NIDEY et al., 2016).

De fato, pais cuidadores sofrem instabilidade financeira diante da necessidade de fazer adaptações ou de abandonar o trabalho. As despesas com a reabilitação e com a saúde da criança envolvem gastos com transporte, medicamentos e consultas, que muitas vezes extrapolam a renda familiar (DANTAS et al., 2019).

Evidencia-se ainda, que o abandono do trabalho é prevalente entre mães, em comparação aos pais, como evidenciado neste estudo. Investigação apontou que as famílias de crianças com fissura de lábio e/ou palato relataram que suas finanças eram impactadas negativamente, pela necessidade de cuidados com o filho (EMEKA et al., 2017).

O impacto econômico relaciona-se ao aumento de custos relacionados aos exames ambulatoriais, necessidade de procedimentos cirúrgicos, retornos para atendimento ambulatorial e internações. (BANNINK et al., 2010; MACHO et al., 2017).

Um estudo, cujo objetivo foi examinar as perspectivas de cuidadores de crianças com distúrbios alimentares, apontou, entre outros, a dificuldade financeira como um obstáculo ao processo reabilitador (SIMIONE et al., 2020). 
Ainda nesse contexto, outra pesquisa apontou desafios enfrentados por familiares para cuidar da criança com traqueostomia no domicílio, incluindo, entre outros, a necessidade de enfrentar a nova realidade, as demandas de cuidado e a dificuldade referente à aquisição de materiais (BOSSA et al., 2019).

Em suma, os achados deste estudo confirmam que a rotina de retornos periódicos para tratamento, internações e a necessidade de insumos especiais, impactam diretamente a vida financeira da família.

A mãe, cuidadora principal, além de prover os cuidados com a criança, é responsável pela gestão do lar, cuidados com outros filhos e do cônjuge, além de cuidar de si própria. Esses fatores podem contribuir para aumento do estresse e da sobrecarga, podendo ocasionar alterações de ordem física e/ou psicológica, conforme relatado pelas participantes deste estudo.

\section{IMPLICAÇÕES RELACIONADAS AO PROCESSO DE CUIDAR}

$\mathrm{Na}$ categoria "implicações relacionadas ao processo de cuidar", a sobrecarga e estresse foram evidenciados. Um resultado similar foi observado em outro estudo (BANHARA et al., 2020).

Salienta-se que a sobrecarga e/ou tensão relacionada ao papel de cuidar, acontece quando o cuidador apresenta respostas negativas, emocionais e/ou físicas, diante das mudanças e demandas do processo de cuidar de alguém com uma deficiência física ou mental. Nesse sentido, uma investigação apontou correlação entre a sobrecarga vivenciada por cuidadores informais e pior percepção da qualidade de vida (ARAÚJO et al., 2019).

Trata-se de um conceito multidimensional que engloba aspectos psicológicos, de saúde, sociais e impactos econômicos da prestação de cuidados. Assim, a sobrecarga é caracterizada pela quantidade de tempo e da assistência prestada (LIMA; SALES; SERAFIM, 2019).

Pode relacionar-se aos fatores objetivos e subjetivos, sendo que, no fator objetivo, destacam-se as atividades voltadas ao ato de cuidar e, no subjetivo, a maneira pela qual o cuidador percebe o seu papel frente ao cuidado (TRETTENE et al., 2017; RIFFIN et al., 2019). 
Identificar a sobrecarga é o primeiro passo para planejar intervenções psicoeducacionais e psicoterapêuticas, visando melhorar a rede de apoio e a capacidade de enfrentamento situacional dos cuidadores, visando melhorar a qualidade da vida dos mesmos, além de contribuir efetivamente para a qualidade dos cuidados por eles prestados (CARO et al., 2017; LOU et al., 2017).

A relação entre a demanda de cuidado e o cuidador é determinada por fatores pessoais dos indivíduos envolvidos, da estrutura familiar existente e do contexto no qual se inserem, nos níveis cultural, social, político e econômico. A depender do contexto, o ato de cuidar torna-se desafiador ou de difícil execução, sendo influenciado pelas dificuldades vivenciadas por ocasião da deficiência, que somadas à responsabilidade do cuidador podem desencadear sobrecarga de atribuições (FERNANDES et al., 2016).

Diversas mudanças no estilo de vida do cuidador são notadas, incluindo o isolamento social e sobrecarga de trabalho (CÂMARA et al., 2016). Em outras palavras, as interações entre as pessoas determinam as ações dos indivíduos que irão agir no contexto onde estão inseridas (CHARON, 2010).

Nesse sentido, uma pesquisa que buscou investigar a associação entre o estresse e a sobrecarga em cuidadores informais de lactentes com Sequência de Robin isolada, demostrou que $45 \%$ apresentaram estresse e sobrecarga. (TRETTENE et al., 2017). Outro estudo que incluiu cuidadores informais de crianças com fissura de lábio e/ou palato, identificou em $43 \%$ deles, níveis moderados e moderados-severos de sobrecarga (RAZERA et al., 2017).

A demanda de cuidados, atribuídos aos cuidadores informais, a falta de preparo para cuidar, a falta de apoio, o nível de dependência da criança, a complexidade do cuidado, a instabilidade do quadro clínico, o risco de complicações e incertezas sobre o prognóstico resultam em sobrecarga, podendo acarretar isolamento social, perda ou extinção do vínculo empregatício e tempo reduzido ou insuficiente para o auto cuidado (PUCCIARELLI et al., 2017; DUNBAR et al., 2018).

Evidencia-se que o papel de cuidar é centralizado na mãe que encontra dificuldades em dividir suas funções, uma vez que os demais membros da família não se consideram aptos a desenvolver essa função. Assim, esses cuidadores, para se adaptarem às necessidades da criança, precisaram abandonar algumas atividades, sejam profissionais ou de 
lazer, desfavorecendo a interação social. Soma-se ainda, o estigma social que enfrentam (CÂMARA et al., 2016; DANTAS et al., 2019).

Nesse sentido, uma investigação apontou a importância de os cuidados serem compartilhados com outros membros da família, minimizando a ocorrência de sobrecarga, estresse, além de implicações negativas na qualidade de vida dos principais cuidadores informais (BANHARA et al., 2020).

Assim, a empatia, uma das mais importantes atividades mentais, torna-se prérequisito para a comunicação simbólica e ao auto desenvolvimento, permitindo ao indivíduo, entre outros, controlar e perceber suas ações, incluindo suas consequências. Em suma, o ato de cuidar decorre das ações e interações entre os envolvidos (CHARON, 2010).

De fato, o ônus da prestação de cuidados está mais relacionado à rejeição social e ao estigma social, do que com as questões de cuidado e adaptação em torno da deficiência da criança. Esse efeito é preocupante, porquanto o isolamento da família implica na retração das redes de apoio social (DANTAS et al., 2019).

Estudando o impacto psicossocial em pais de crianças com deficiência, resultados semelhantes aos do corrente estudo foram encontrados, permitindo inferir que essas mães cuidadoras são pressionadas pelas necessidades imediatas e pelos preconceitos sociais, apresentando tendência a se isolarem. Esse isolamento reduz progressivamente a rede e os recursos por elas potencializados num ciclo negativo de necessidades crescentes e recursos decrescentes, reduzindo também os papéis sociais das mães (DANTAS et al., 2019).

Como cuidadora principal, a mãe aceita maiores responsabilidades que os outros membros da família e tem mais atribuições de cuidados do que o pai. Tradicionalmente, espera-se que as mulheres promovam o ato de cuidar, nutrir e ajudar. $\mathrm{O}$ ônus do cuidador é o resultado da necessidade de cuidados, sendo físico, psicológico e social, causando um desequilíbrio entre demandas de cuidado e outras responsabilidades, como deveres pessoais, sociais e papéis no trabalho e na família (TRETTENE et al., 2017).

$\mathrm{Na}$ verdade, o ser humano, a partir do significado que tem do outro, baseando-se em sua interação, orienta seus atos, ou seja; a prioridade para essas mães cuidadoras passa a ser o filho com suas necessidades (CHARON et al., 2010).

Nossos achados apontam que as dimensões mais influenciadas foram: as interações familiares, o sentimento de estreitamento do relacionamento dentro da família, 
necessidade de comunicação com o parceiro, falta de tempo adequado para outros membros da família e os demais filhos; achados esses, que corroboram com outro estudo que incluiu cuidadores de crianças com fissura de lábio e/ou palato, menores de um ano (MACHO et al., 2017).

A maneira como as pessoas vivenciam a situação, alicerça-se na capacidade que possuem de utilizar seu raciocínio e capacidade de simbolização para interpretar e adaptar-se flexivelmente às circunstâncias (CHARON, 2010).

Ressalta-se que as relações familiares são fundamentais para se enfrentar adequadamente doenças crônicas e o prolongado tratamento, que comumente é necessário nessas condições. Por isso, o acompanhamento familiar é fundamental para manter bons indicadores de saúde mental, suporte social e qualidade de vida (LIMA; SALES; SERAFIM, 2019). Diferentes investigações apontaram correlação entre a saúde mental dos cuidadores informais e a qualidade na realização dos cuidados (SALO; SCHUNCK; HUMPHREYS, 2020; COSTA et al., 2020).

\section{IMPLICAÇÕES REFERENTES AO ACESSO DOS SERVIÇOS DE SAÚDE}

Outra categoria desvelada neste estudo referiu-se às "implicações referentes ao acesso dos serviços de saúde", onde observou-se que o acesso ao tratamento especializado e o olhar humanizado da equipe apresentaram-se como facetas importantes no processo de reabilitação. Nesse sentido, uma investigação pontuou a ajuda técnica e o apoio à família, como sendo de grande importância para as mães (LINDBERG; BERGLUND, 2014).

A sobrecarga não se relaciona somente às demandas de cuidado, mas também aos sentimentos que acompanham a mãe, como a preocupação com a sobrevivência da criança, o sentimento de culpa, a impotência e o desconhecimento sobre como cuidar. Mais do que isso, advoga-se que as dificuldades também se dissipam no ambiente familiar e demandam a produção de conhecimento a respeito das necessidades inerentes ao cuidado (DANTAS et al; 2019), reforçando que o acesso ao tratamento especializado e informações coerentes diminuem essas preocupações e facilitam o funcionamento familiar.

Confiar na equipe de tratamento reduz o estresse (ZEYTINOĞLU et al., 2016). Além disso, a alta satisfação com os cuidados de saúde que pais e filhos receberam após o diagnóstico da fissura é um fator preditivo essencial de bem-estar (KUMAR et al., 2020). 
A necessidade de informação e o acesso às orientações coerentes, confiáveis e atuais, devem ocorrer de forma gradual, e não apenas de uma única vez, reforçando assim, a importância da integração do cuidador em todo processo de hospitalização (20). A mudança de responsabilidade no dia-a-dia e as decisões de cuidados atreladas ao cuidador, exigem que os profissionais de saúde assumam o status de colaborador, atuando em parceria com os pais e desenvolvendo suas potencialidades (FERNANDES; ANGELO, 2016).

O cuidador espera que os profissionais de saúde respondam honestamente as perguntas sobre a condição do paciente e possíveis alterações (BOLLA et al., 2013; LINDBERG; BERGLUND, 2014; LIMA; SALES; SERAFIM, 2019). Ainda, informações não fornecidas aos cuidadores podem resultar em incerteza e ansiedade (SMITH; CHEATER; BEKKER, 2015).

Em suma, reafirmam-se as premissas do Interacionismo Simbólico, que discerne que o ser humano atribui um significado a partir das suas relações sociais, ou seja; ser amparado por um profissional o faz depreender que a situação pode ser enfrentada, sendo menos complicada do que parece (CHARON, 2010).

Ressalta-se que a comunicação efetiva junto aos familiares, em especial com o cuidador principal, favorece o estabelecimento de vínculo com os profissionais, propiciando o compartilhamento efetivo de informações necessárias para o aumento da autoconfiança, para a realização do cuidado no domicílio (VIANA et al., 2019).

O reconhecimento das necessidades do cuidador, enquanto sujeito ativo, é de suma importância, e inclui a promoção de estratégias de comunicação positivas para o desenvolvimento de um relacionamento eficaz entre equipe e cuidador. Assim, fornecer informação aos cuidadores favorece a qualidade dos cuidados (FERNANDES; ANGELO, 2016).

Outro aspecto importante desvelado, referiu-se ao treinamento do cuidador para a alta hospitalar, no qual o mesmo é ensinado e treinado quanto os cuidados necessários ao lactente no domicílio. Na instituição, cenário desta pesquisa, o cuidador recebe treinamento durante a internação de seu filho, visando a continuidade/manutenção dos cuidados com qualidade e segurança após a alta hospitalar, ou seja; trabalha-se o empoderamento do cuidador conforme recomendado na literatura (MARCH, 2017; ALSAEED et al., 2018; BELUCI et al., 2019). 
Os motivos que pesam na integração e prestação de cuidados ao paciente após a alta devem ser considerados pelos profissionais, no sentido de um melhor apoio, formação e treinamento dos cuidadores informais, e essa atuação deve ser incluída nas rotinas de cuidados (CARVALHO; ARAÚJO; VERÍSSIMO, 2019).

Ainda na categoria "implicações referentes ao acesso dos serviços de saúde", constatou-se que as famílias dos lactentes, sofreram entre idas e vindas, em serviços que não acolheram suas demandas, e tampouco os referenciaram ao serviço especializado de maneira efetiva. $\mathrm{O}$ acesso ao tratamento e às informações de forma adequada são essenciais no processo de reabilitação, além de trazer conforto aos pais e melhorar a qualidade de vida do paciente (BENNETT et al., 2018).

Devido às incertezas e informações limitadas, os pais enfrentam vários desafios quanto ao tratamento e dificuldade de atendimento por parte das equipes de contra referência, tornando mais difícil e exaustiva a incumbência de cuidar (FERNANDES; ANGELO, 2016).

Frente a esse cenário, fica evidente a necessidade dos programas de educação e formação de profissionais de saúde fora dos centros especializados, conscientização pública sobre as fissuras orofaciais e as síndromes relacionadas, além de programas de apoio social. Quanto mais rara e complexa for a doença, mais aconselhamento especializado faz-se necessário (BELUCI et al., 2019).

A experiência vivenciada pelos participantes deste estudo referente aos serviços de saúde foi negativa, pois encontraram inúmeras dificuldades, incluindo informações desencontradas e baixa efetividade em relação aos encaminhamentos. Um resultado similar foi observado em outra pesquisa (BOLLA et al., 2013).

Os centros de reabilitação geralmente estão distantes dos pacientes e suas famílias. Assim, para garantir o acesso e a permanência no tratamento, necessitam do apoio de políticas públicas no que tange o transporte e ajuda de custo para hospedagem e alimentação. Para provimento desses benefícios, pacientes e familiares recorrem ao Tratamento Fora do Domicílio (TFD) (BRASIL, 1999; FOLLENT et al.; 2017).

Contudo, o acesso à efetivação dessa portaria nem sempre é viabilizado, sendo necessário, com frequência, recorrer à judicialização para garantir esse direito, conforme os relatos das mães cuidadoras, do presente estudo. 
O apoio financeiro permaneceu como barreira de acesso. No entanto, questões de organização do sistema de saúde, como falta de orientação ao paciente sobre os serviços disponíveis e má coordenação na indicação do encaminhamento, também prevaleceu (IZE et al.; 2019). Outros estudos apontam o transporte e os custos com viagem como principais barreiras de acesso ao tratamento (MASSENBURG et al., 2016; FERNANDES; ANGELO, 2016).

Identificou-se que a falta de efetivação dos direitos gera prejuízos ao tratamento, incluindo as transferências para centros especializados, faltas nas consultas e retornos, e consequentemente, atrasos no processo de reabilitação.

Chama a atenção, o fato dos maiores motivos para judicialização no SUS, referirem-se aos pedidos de medicação, embora estivessem contemplados nas tabelas do SUS e serem de baixo custo, apontando a falta de organização de alguns serviços públicos.

Um estudo que incluiu cuidadores de crianças com fissuras orofaciais, apontou que estes vivenciaram deficiências no sistema de saúde, falta de conscientização pública e apoio social insuficiente (HLONGWA et al., 2018).

Assim, além das implicações frente ao diagnóstico, que dependerá muito das experiências prévias da mãe e da família, e de como percebem este momento, e se reorganizam frente a ele, outras questões, como encaminhamento efetivo aos centros especializados e a garantia de acesso às políticas públicas que asseguram o acesso e continuidade do tratamento, são fatores, que, se funcionarem de forma efetiva, podem tornar este processo mais ameno ou menos traumático.

Uma meta-síntese qualitativa, cujo objetivo foi identificar as repercussões do nascimento e do cuidado de um filho com deficiência múltipla na família, apontou que vivenciam dificuldades advindas das representações das malformações e dos encargos do cuidado, com repercussões negativas na saúde, convívio familiar e social, necessidade de reestruturação e dificuldades financeiras (DANTAS et al., 2019).

Assim, faz-se necessária a implementação e monitoramento de modelos assistenciais centrados na família para apoiar não somente os cuidadores informais principais, mas toda a unidade familiar no cuidado dessas crianças (FOLLENT et., 2017).

No entanto, embora essa necessidade seja emergente, configura-se como um desafio aos profissionais de saúde por necessitarem de preparo que os permita transcender o 
cuidado meramente técnico do contexto hospitalar para uma prática assistencial que vislumbre a família como protagonista na promoção da qualidade de vida dessas crianças (DIAS et al., 2019).

\section{LIMITAÇÕES DO ESTUDO}

Considera-se uma limitação deste estudo, o fato de que uma única entrevista pode não ter sido suficiente para capturar os sentidos e significados atribuídos pelos participantes referentes ao fenômeno estudado.

\section{CONTRIBUIÇÕES DO ESTUDO À PRÁTICA CLÍNICA}

Os benefícios deste estudo são evidentes e incluem o apontamento de dificuldades específicas enfrentadas por cuidadores informais primários, além de áreas a serem melhoradas referentes ao apoio, tanto para eles, como para a família. Estes achados reforçam a necessidade de modelos assistenciais centrados na família. 




\section{CONSIDERAÇÕES FINAIS}

Buscou-se neste estudo, compreender as implicações psicossociais vivenciadas por pais cuidadores decorrentes do cuidado do filho com fissura de lábio e/ou palato associados às síndromes. Para tal, optou-se por utilizar o método de pesquisa qualitativo, sendo assertivo, uma vez que possibilitou o alcance do objetivo, plenamente.

Observou-se que, embora a condição da criança seja para os pais cuidadores e à família um momento difícil e conflituoso após o nascimento, a partir da interação e da maneira como vivenciam essa simbologia, desenvolvem capacidades adaptativas que desencadeiam ações que culminam em assumir papéis que incluem o de cuidador informal. Nesse contexto, a figura materna desponta como protagonista do cuidado do filho com fissura de lábio e/ou palato associada à síndrome.

Contudo, frente à realidade que vivenciam, enfrentam adversidades ou dificuldades de ordem psicoemocionais, financeiras, físicas, de apoio familiar e social, apontando a complexidade do processo de cuidar que vai além dos cuidados propriamente ditos.

Por fim, desvelou-se o quanto as implicações psicossociais vivenciadas por esses cuidadores são multifacetadas e complexas. Conhecê-las, viabiliza o planejamento e a implementação de ações que contribuam, além do processo reabilitador das crianças, para a saúde e qualidade de vida daqueles que cuidam. 



\section{REFERÊNCIAS}





\section{REFERÊNCIAS}

Alsaeed D, Furniss D, Blandford A, Smith F, Orlu M. Carers' experiences of home enteral feeding: A survey exploring medicines administration challenges and strategies. J Clin Pharm Ther. 2018;43(3):359-365. doi: https://doi.org/10.1111/jcpt.12664

Araújo MGO, Dutra MOM, Freitas CCDL, Guedes TG, Souza FS, Baptista RS. Caring for the carer: quality of life and burden of female caregivers. Rev Bras Enferm. 2019;72(3):728-36. doi: http://dx.doi.org/10.1590/0034-7167-2018-0334

Banhara FL, Farinha FT, Bom CG, Razera APR, Tabaquim MLM, Trettene AS. Parental care for infants with feeding tube: psychosocial repercussions. Rev Bras Enferm. 2020;73(2):e20180360. doi: http://dx.doi.org/10.1590/0034-7167-2018-0360

Bannink N, Maliepaard M, Raat H, Joosten KFM, Mathijssen IMJ. Health-related quality of life in children an adolescents with syndromic craniosynostosis. J Plast Reconstr Aesthet Surg. 2010;63(12):1972-81. doi: https://doi.org/10.1016/j.bjps.2010.01.036

Bardin L. Análise de conteúdo. São Paulo: Edições 70, 2013.

Beluci ML, Mondini CCSD, Trettene AS, Dantas RAS. Correlation between quality of life and burden of family caregivers of infants with cleft lip and palate. Rev Esc Enferm USP. 2019;53:e03432. doi: http://dx.doi.org/10.1590/S1980-220X2017047

Bennett KG, Ranganathan K, Patterson AK, Baker MK, Vercler CJ, Kasten SJ, et al. Caregiver-reported outcomes and barriers to care among patients with cleft lip and palate.

Plast Reconstr Surg. 2018;142(6):884-91. doi: https://doi.org/10.1097/PRS.0000000000004987

Bolla BA, Fulconi SN, Baltor MRR, Dupas G. Cuidado da criança com anomalia congênita: a experiência da família. Esc Anna Nery. 2013;17(2):284-90. doi: https://doi.org/10.1590/S1414-81452013000200012

Bossa PMA, Pacheco STA, Araújo BBM, Nunes MDR, Silva LF, Cardoso JMRM. Home care challenges facing families of children using a tracheostomy cannula. Rev Enferm UERJ. 2019;27:e43335. doi: http://dx.doi.org/10.12957/reuerj.2019.43335

Brasil. Ministério da Saúde. Secretaria de Atenção à Saúde. Portaria no 55, de 24 de fevereiro de 1999. Dispõe sobre a rotina do Tratamento Fora de Domicilio no Sistema Único de Saúde SUS, com inclusão dos procedimentos específicos na tabela de procedimentos do Sistema de Informações Ambulatoriais do SIA/SUS e dá outras providências [cited 2020 Jun 03].

Available

from:

https://bvsms.saude.gov.br/bvs/saudelegis/sas/1999/prt0055_24_02_1999.html

Câmara FS, Martins WLL, Moura MLN, Melo CS, Medeiros NSR, Gadelha ECM, et al. Perfil do cuidador de pessoas com deficiência. Rev Bras Cie Saúde. 2016;20(4):269-76. doi: http://dx.doi.org/10.4034/RBCS.2016.20.04.02

Caro CC, Mendes PV, Costa JD, Nock LJ, Cruz DM. Independence and cognition post-stroke and its relationship to burden and quality of life of family caregivers. Top Stroke Rehabil. 2017;24(3):194-199. doi: https://doi.org/10.1080/10749357.2016.1234224. 
Carvalho A, Araújo LJP, Veríssimo MT. When long-term care comes to an end: informal caregivers' perspectives on patient discharge. Rev Enf Ref. 2019;4(22):107-15. doi: https://doi.org/10.12707/RIV19023

Charon JM. Symbolic Interacionism: an introduction, an interpretation, as integration. $10^{\text {th }}$ Ed. Boston: Prentice Hall; 2010.

Costa ADPV, Santos LM, Feitosa CA, de Miranda CT. Maternal common mental disorder over time and asthma control: the role of social support. Pediatr Allergy Immunol. 2020 Mar 23. doi: https://doi.org/10.1111/pai.13249

Dantas KO, Neves RF, Ribeiro KSQS, Brito GEG, Batista MC. Repercussions on the family from the birth and care of children with multiple disabilities: a qualitative meta-synthesis. Cad Saúde Pública 2019;35(6):e00157918. doi: http://dx.doi.org/10.1590/0102-311X00157918

Dias BC, Ichisato SMS, Marchetti MA, Neves ET, Higarashi IH, Marcon SS. Challenges of family caregivers of children with special needs of multiple, complex and continuing care at home. Esc Anna Nery Rev Enferm. 2019;23(1):e20180127. doi: http://dx.doi.org/10.1590/2177-9465-EAN-2018-0127

Dunbar SB, Khanjou OA, Bakas T, Hunt G, Kirch RA, Leib AR, et al. Projected costs of informal caregiving for cardiovascular disease: 2015 to 2035. Circulation. 2018;137(19):e558-e577. doi: https://doi.org/10.1161/CIR.0000000000000570

Emeka CI, Adeyemo WL, Ladeinde AL, Butali A. A comparative study of quality of life of families with children born with cleft lip and/or palate before and after surgical treatment. $\mathrm{J}$

Korean Assoc Oral Maxillofac Surg. 2017;43(4):247-255. doi: https://doi.org/10.5125/jkaoms.2017.43.4.247

Fernandes CS, Angelo M. Family caregivers: what do they need? An integrative review. Rev Esc Enferm USP. 2016;50(4):672-678. doi: http://dx.doi.org/10.1590/S0080$\underline{623420160000500019}$

Follent AM, Rumbach AF, Ward EC, Marshall J, Dodrill P, Lewindon P. Dysphagia and feeding difficulties post-pediatric ingestion injury: perspectives of the primary caregiver. Int $\mathrm{J}$ Pediatr Otorhinolaryngol. 2017;103:20-28. doi: https://doi.org/10.1016/j.ijporl.2017.09.013

Fontanella BJB, Ricas J, Turato ER. Amostragem por saturação em pesquisas qualitativas em saúde: contribuições teóricas. Cad Saúde Pública (Rio de Janeiro) [Internet]. 2008 [cited 2020 Jun 03];24(1):17-27. Available from: https://www.scielo.br/pdf/csp/v24n1/02.pdf

Freitas JAS, Neves LT, Almeida ALPF, Garib DG, Trindade-Suedam IK, Yaedú RYF, et al. Rehabilitative treatment of cleft lip and palate: experience of the Hospital for Rehabilitation of Craniofacial Anomalies/USP (HRAC/USP) - Part 1: overall aspects. J Appl Oral Sci. 2012;20(2):9-15. doi: https://doi.org/10.1590/S1678-77572012000100003.

Graciano MIG, Souza EG, Rosa JA, Blattner SHB. Validação de conteúdo de um instrumento de avaliação socioeconômica no âmbito do Serviço Social. Rev do Instituto de Pesquisas e 
Estudos: Construindo o Serviço Social [Internet]. 2015 [cited 2020 Jun 01];19(36):29-57. Available from: http://ojs.ite.edu.br/index.php/css/article/viewFile/214/253

Hlongwa P, Rispel LC. "People look and ask lots of questions": caregivers' perceptions of healthcare provision and support for children born with cleft lip and palate. BMC Public Health. 2018;18(1):506. doi: https://doi.org/10.1186/s12889-018-5421-x.

Ise A, Menezes C, Batista Neto J, Saluja S, Amundson JR, Jenny H, Massenburg B, Citron I, Alonso N. Patient-perceived barriers to accessing cleft care at a tertiary referral center in São

Paulo, Brazil. Cleft Palate Craniofac J. 2019;56(5):639-645. doi: https://doi.org/10.1177/1055665618796018

Kumar K, Kumar S, Mehrotra D, Gupta S, Khandpur S, Mishra RK. A psychologic assessment of the parents of patients with cleft lip and palate. J Craniofac Surg. 2020;31(1):58-61. doi: http://dx.doi.org/10.1097/SCS.0000000000005835

Lima AGT, Sales CCS, Serafim WFL. Burden, depression and anxiety in primary caregivers of children and adolescents in renal replacement therapy. J Bras Nefrol. 2019;41(3):356-63. doi: https://doi.org/10.1590/2175-8239-JBN-2018-0039

Lindberg N, Berglund AL. Mothers' experiences of feeding babies born with cleft lip and palate. Scand J Caring Sci. 2014;28(1):66-73. doi: https://doi.org/10.1111/scs.12048

Lou S, Carstensen K, Jørgensen CR, Nielsen CP. Stroke patients and informal carers experiences with life after stroke: an overview of qualitative systematic reviews. Disabil Rehabil. 2017;39(3):301-13. doi: https://doi.org/10.3109/09638288.2016.1140836

Luquetti DV, Brajcich MR, Stock NM, Heike CL, Johns AL. Health care and psychosocial experiences of individuals with craniofacial microsomia: patient and caregivers perspectives.

Int J Pediatr Otorhinolaryngol. 2018;107:164-75. doi:

https://doi.org/10.1016/j.ijporl.2018.02.007

Macho P, Bohac M, Fedeles J Jr, Fekiacova D, Fedeles J Sr. Impact of cleft lip and/or palate in children on family quality of life before and after reconstructive surgery. Bratisl Med $\mathrm{J}$. 2017;118(6):370-3. doi: https://doi.org/10.4149/BLL_2017_070

March S. Parents' perceptions during the transition to home for their child with a congenital heart defect: How can we support families of children with hypoplastic left heart syndrome? J Spec Pediatr Nurs. 2017;22:e12185. doi: https://doi.org/10.1111/jspn.12185

Massenburg BB, Jenny HE, Saluja S, Meara JG, Shrime MG, Alonso N. Barriers to cleft lip and palate repair around the world. J Craniofac Surg. 2016;27(7):1741-45. doi: http://dx.doi.org/10.1097/SCS.0000000000003038

Minayo MCS. O desafio do conhecimento: pesquisa qualitativa em saúde. 13 $3^{a}$ ed. São Paulo: Hucitec, 2013.

Mondini CCSD, Fontes CMB, Trettene AS, Cianciarullo TI, Lazarini IM. Applicability of Orem: training of caregiver of infant with Robin Sequence. Rev Bras Enferm. 2018;71(Suppl.3):1469-73. doi: https://doi.org/10.1590/0034-7167-2016-0562 
Nidey N, Uribe LMM, Marazita MM, Wehby GL. Psychosocial well-Being of parents of children with oral clefts. Child Care Health Dev. 2016;42(1):42-50. doi: https://doi.org/10.1111/cch.12276

O'Hanlon K, Camic PM, Shearer J. Factors associated with parental adaptation to having a child with a cleft lip and/or palate: the impact of parental diagnosis. Cleft Palate Craniofac J. 2012;49(6):718-29. doi: https://doi.org/10.1597/10-018

Pucciarelli G, Vellone E, Savini S, Simeone S, Ausili D, Alvaro R. et al. Roles of changing physical function and caregiver burden on quality of life in stroke: a longitudinal dyadic analysis. Stroke. 2017;48(3):733-9. doi: https://doi.org/10.1161/STROKEAHA.116.014989

Razera APR, Trettene AS, Niquerito AV, Tabaquim MLM. Study of burden among caregivers of children with cleft lip and palate. Paidéia (Ribeirão Preto). 2017;27(68):3-10. doi: https://doi.org/10.1590/1982-43272768201701

Riffin C, Van Ness PH, Wolff JL, Fried T. Multifactorial examination of caregiver burden in a national sample of family and unpaid caregivers. J Am Geriatr Soc. 2019;67(2):277-283. doi: https://doi.org/10.1111/jgs.15664

Salmen ICDM, Maques IL. In situ and home care nasopharyngeal intubation improves respiratory condition and prevents surgical procedures in early infancy of severe cases of

Robin Sequence. Biomed Res Int. 2015;2015:608905. doi: https://doi.org/10.1155/2015/608905

Salo VC, Schunck SJ, Humphreys KL. Depressive symptoms in parents are associated with reduced empathy toward their young children. PLoS One. 2020;15(3):e0230636. doi: https://doi.org/10.1371/journal.pone.0230636

Simione M, Dartley AN, Cooper-Vince C, Martin V, Hartnick C, Taveras EM, et al. Familycentered outcomes that matter most to parents: a pediatric feeding disorders qualitative study. J Pediatr Gastroenterol Nutr. 2020. doi: https://doi.org/10.1097/MPG.0000000000002741

Smith J, Cheater F, Bekker H. Parents' experiences of living with a child with a long $\square$ term condition: a rapid structured review of the literature. Health Expect. 2015;18(4):452-74. doi: https://doi.org/10.1111/hex.12040

Tong A, Sainsbury P, Craig J. Consolidated criteria for reporting qualitative research (COREQ): a 32-item checklist for interviews and focus groups. Int $\mathbf{J}$ Qual Health Care. 2007;19(6):349-57. doi: https://doi.org/10.1093/intqhc/mzm042

Trettene AS, Turbiani ACA, Razera APR, Souza NFH, Turbiani DR, Silva JSG. Estresse e sobrecarga em cuidadores informais de crianças com Sequência de Robin Isolada. J Nurs UFPE on line [Internet]. 2017 [cited 2020 Jun 03];11(8):3013-20. Available from: https://10.5205/reuol.11064-98681-4-ED.1108201704

Viana ACG, Alves AMPM, Lopes MEL, Lima DRA, Batista PSS, Vasconcelos MF. Mães de bebê malformado: percepção sobre orientações de enfermeiro. Rev Enferm UFPE on line. 2019;13:e239825 doi: https://doi.org/10.5205/1981-8963.2019.239825 
Xiao Y, Taub MA, Ruczinski I, Begum F, Hetmanski JB, Schwender H, et al. Evidence for SNP-SNP interaction identified through targeted sequencing of cleft case-parent trios. Genet Epidemiol Sci. 2017;41(3):244-50. doi: https://doi.org/10.1002/gepi.22023

Zeytinoğlu S, Davey MP, Crerand C, Fisher K. Fathers of children born with cleft lip and palate: impact of the timing of diagnosis. Fam Syst Health. 2016;34(2):150-8. doi: http://dx.doi.org/10.1037/fsh0000198 

APÊNDICES 



\section{APÊNDICE A}

\section{QUESTIONÁRIO SOCIODEMOGRÁFICO}

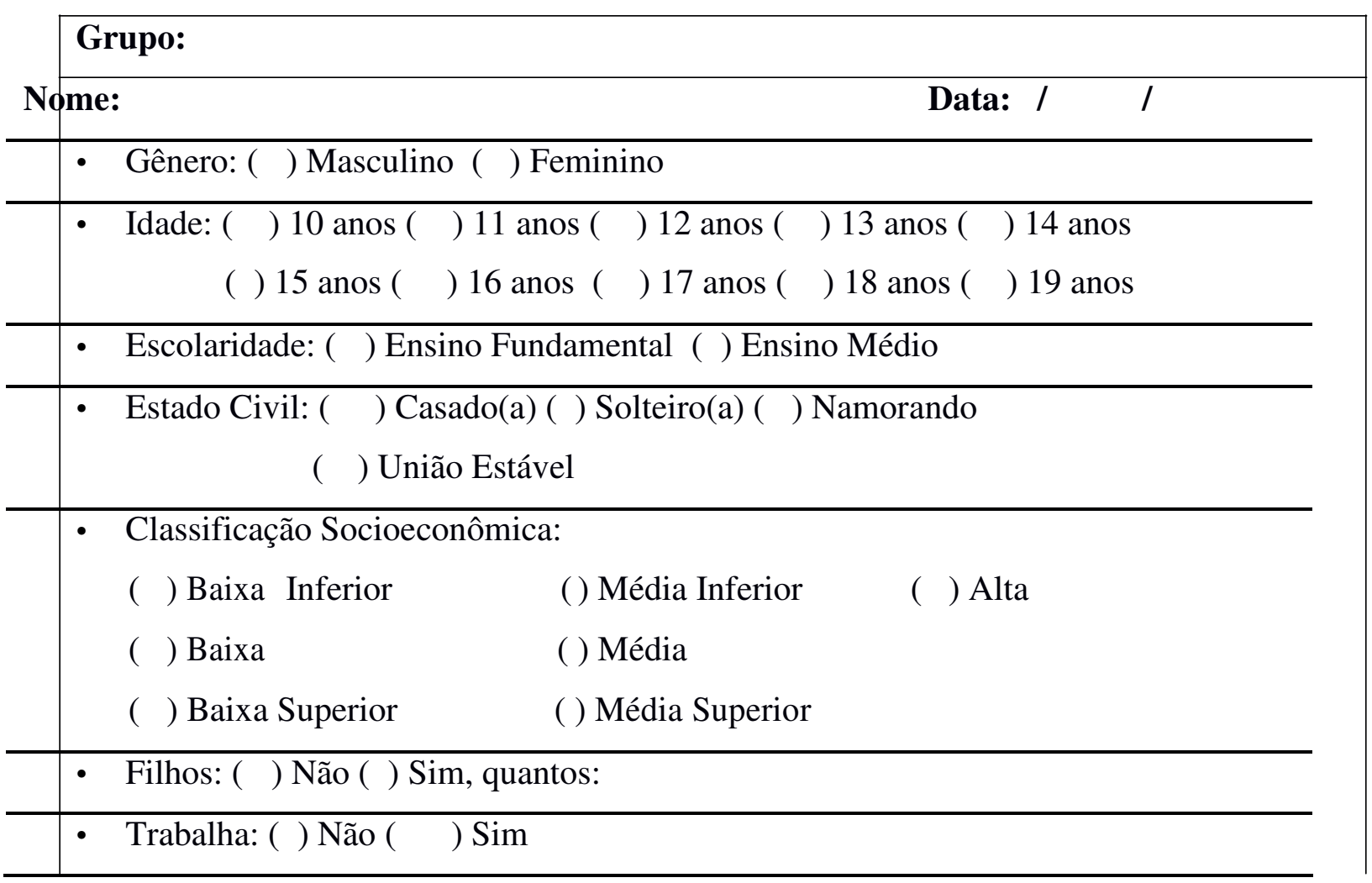




\section{APÊNDICE B}

\section{TERMO DE CONSENTIMENTO LIVRE E ESCLARECIDO}

Pelo presente instrumento que atende às exigências legais, o Sr. (a)

portador da cédula de identidade está sendo convidado(a) como voluntário(a) a participar da pesquisa: "O cuidar do lactente com fissura de lábio e/ou palato associada à síndrome: repercussões psicossociais vivenciadas por pais cuidadores", realizada por Rayanne Meyer Barduzzi, CRESS: 40483, sob orientação do Prof. Dr. Armando dos Santos Trettene, COREN-SP: 129174.

O motivo que nos leva a estudar este assunto é entender como tem sido para você cuidar de seu filho com fissura, e o que isso tem afetado as suas atividades do seu dia a dia. Para participar da pesquisa você terá que responder algumas questões, como, por exemplo, o que deixou de fazer para se dedicar ao cuidado de seu filho com fissura. Suas respostas serão gravadas para que os pesquisadores possam analisá-las depois.

O tempo que você gastará para responder as perguntas é de aproximadamente 30 minutos. Você responderá as perguntas em uma sala onde só você e eu estaremos, ou, com mais alguém que você queira.

Esperamos, com a realização desse estudo, entender como tem sido para você cuidar de seu filho com fissura, e o que isso tem afetado as suas atividades do seu dia a dia. Com os resultados, nós vamos pensar em maneiras de ajudar os pais que cuidam de seus filhos com fissura, a terem maior qualidade de vida e bem-estar.

Os benefícios esperados com o desenvolvimento desta pesquisa é propor estratégias que diminuam o estresse e a sobrecarga, que geralmente os pais cuidadores apresentam.

Os riscos contidos no presente estudo são inerentes às pesquisas desse tipo, ou seja, você poderá lembrar-se de coisas, situações ou pessoas ruins, e com isso, se sentir triste. Para diminuir o risco disto acontecer, você responderá as perguntas em uma sala onde só você e eu estaremos, ou outra pessoa que você queira.

Você pode recusar-se a participar da pesquisa e/ou retirar seu consentimento em qualquer fase da pesquisa, sem penalização alguma. Ressalta-se que todas as informações prestadas tornar-se-ão confidenciais e guardadas por força de sigilo profissional (Art. 15ำ do Código de Ética do Assistente Social), durante todas as fases da pesquisa, ou seja, seu nome não aparecerá em hipótese alguma. Ninguém, além de nós, saberá que você participou da pesquisa. 
Você não terá qualquer tipo de despesa para participação da pesquisa, considerando que a mesma será realizada no dia em que você estará acompanhando seu filho, que estará sendo atendido aqui no hospital. Sendo assim, não haverá qualquer despesa específica decorrente da participação na pesquisa. Entretanto, caso ocorra algum dano decorrente da participação no estudo, você será devidamente indenizado.

Para qualquer tipo de esclarecimentos e dúvidas sobre sua participação na pesquisa, você poderá entrar em contato com o pesquisador por meio do Endereço Institucional: Rua Silvio Marchione, 3-20 - Vila Universitária - CEP 17012-900 - Bauru/SP, ou pelo telefone (14) 3235-8173 ou(14) 99781-0608 e e-mail: rayannemeyer@usp.br. Para denúncias e/ou reclamações, entrar em contato com Comitê de Ética em Pesquisa do HRAC-USP, Rua Silvio Marchione, 3-20 - Vila Universitária - CEP 17012-900 - Bauru/SP, de segunda à sexta, das 8 às 18 horas, ou pelo telefone (14) 3235-8421, e-mail:

cephrac@usp.br.

Eu, portador da cédula de identidade após leitura das informações neste TERMO DE CONSENTIMENTO LIVRE E ESCLARECIDO, concordo em participar da pesquisa e assino este documento em duas vias, sendo que uma via ficará comigo e outra com o pesquisador.

Bauru, SP, de de

Assinatura do Pesquisador

Assinatura do Participante da Pesquisa

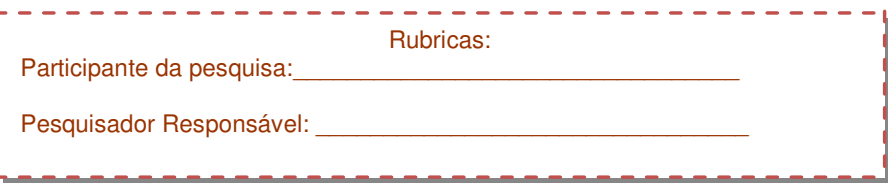




\section{USP - HOSPITAL DE REABILITAÇÃO DE ANOMALIAS CRANIOFACIAIS}

\section{PARECER CONSUBSTANCIADO DO CEP}

\section{DADOS DO PROJETO DE PESQUISA}

Título da Pesquisa: O cuidar do lactente com fissura de lábio e/ou palato associada à síndrome: repercussões psicossociais vivenciadas por pais cuidadores

Pesquisador: Rayanne Meyer Barduzzi

Área Temática:

Versão: 2

CAAE: 04319418.0 .0000 .5441

Instituição Proponente: Hospital de Reabilitação de Anomalias Craniofaciais da USP

Patrocinador Principal: Financiamento Próprio

\section{DADOS DO PARECER}

Número do Parecer: 3.112 .342

\section{Apresentação do Projeto:}

Trata-se de um projeto de Dissertação de mestrado, de autoria de Rayanne Meyer Barduzzi sob orientação de Armando dos Santos Tretenne, reapresentado para alterações no TCLE e na hipótese cujo objetivo: Compreender as implicações psicossociais vivenciadas por pais cuidadores decorrentes do cuidado do filho com fissura de lábio e/ou palato associada à síndrome. Método: Pretende-se realizar um estudo analítico, descritivo, de enfoque qualitativo. Como referencial teórico será utilizado o Interacionismo Simbólico e como referencial metodológico, a Análise de Conteúdo Temática. O estudo será desenvolvido em um hospital público, terciário, de referência no atendimento de pacientes com anomalias craniofaciais, incluindo as fissuras de lábio e/ou palato, e síndromes relacionadas, situado no interior de São Paulo, Brasil.A amostra será não probabilística, intencional e por conveniência, definida por saturação teórica. Os critérios de inclusão serão: ser pai/mãe ou cuidador informal principal do lactente e estar acompanhando-o durante a segunda internação, na Unidade de Cuidados Semi-intensivos. Para a coleta de dados será utilizada a entrevista estruturada com as seguintes perguntas:

Como tem sido para você cuidar de seu filho? Quais foram às principais mudanças em suas atividades diárias depois que começou a cuidar de seu filho? Quais são as suas maiores dificuldades em cuidar de seu filho? Você se sente apoiado? Você conseguiu acessar os recursos comunitários (TFD/Posto de Saúde/Carona Amiga/BPC) para manutenção e continuidade do tratamento? As entrevistas ocorrerão em ambiente privativo, durante a internação dos lactentes,

Endereço: Rua Silvio Marchione, 3-20

Bairro: Vila Nova Cidade Universitária

UF: SP Municipio: BAURU

Telefone: (14)3235-8421 Fax: (14)3234-7818 E-mail: cephrac@usp.br 


\section{USP - HOSPITAL DE REABILITAÇÃO DE ANOMALIAS CRANIOFACIAIS}

Continuação do Parecer: 3.112.342

em horário pertinente aos pais, e serão gravadas em aparelho de áudio digital. Após cada entrevista, o conteúdo das gravações será transcrito na íntegra visando facilitar o processo de análise dos dados emergentes, além de aprimorar e aprofundar a entrevista posterior. O tempo médio de duração da entrevista será de 30 minutos. Ainda, os participantes serão caracterizados segundo: idade, sexo, estado civil, número de filhos, escolaridade e classificação socioeconômica. A coleta de dados ocorrerá entre janeiro e abril de 2019. A pesquisa se iniciará após aprovação do Comitê de Ética em Pesquisa do Hospital.

\section{Objetivo da Pesquisa:}

Objetivo: Compreender as implicações psicossociais vivenciadas por pais cuidadores decorrentes do cuidado do filho com fissura de lábio e/ou palato associada à síndrome. Método: Pretende-se realizar um estudo analítico, descritivo, de enfoque qualitativo.

\section{Avaliação dos Riscos e Benefícios:}

Os riscos contidos no presente estudo são inerentes a pesquisas desse tipo, e podem incluir algum grau de constrangimento, lembranças negativas e exacerbação de sentimentos negativos, como a culpa. Para minimizar tais riscos, a coleta de dados será realizada em ambiente privativo e individualizada.

Benefícios:

Os benefícios esperados com o desenvolvimento do presente estudo constituem importante contribuição, uma vez que viabilizam o planejamento de intervenções que possam contribuir para facilitar o processo de cuidar e favoreçam o bem-estar e a saúde também de quem cuida. Ainda, deve-se considerar que o sucesso do processo reabilitador e a qualidade dos cuidados prestados dependem, em muito, da saúde física, emocional e psicossocial dos cuidadores. Ressalta-se que as implicações advindas do cuidado podem interferir de maneira desfavorável no processo de cuidar.

Assim, torna-se de suma importância desvelar as implicações psicossociais vivenciadas por esses cuidadores.

\section{Comentários e Considerações sobre a Pesquisa:}

O estudo tem mérito científico e poderá contribuir com a atuação da assistência social prestada a estes pacientes.

\section{Considerações sobre os Termos de apresentação obrigatória:}

Carta de encaminhamento;

Formulário HRAC;

Endereço: Rua Silvio Marchione, 3-20 


\section{USP - HOSPITAL DE REABILITAÇÃO DE

Continuação do Parecer: 3.112.342

Folha de Rosto da Plataforma Brasil;

Termo de Consentimento Livre e Esclarecido;

Termo de Assentimento;

Termo de Compromisso, Confidencialidade e Autorização de Utilização de Dados em Projetos de Pesquisa

Termo de Permissão para uso de Registros para Fins Científicos;

Termo de Compromisso de Tornar Públicos os Resultados da Pesquisa e Destinação de Materiais ou Dados Coletados;

Termo de Compromisso do Pesquisador Responsável.

\section{Recomendações:}

Não há.

\section{Conclusões ou Pendências e Lista de Inadequações:}

Os autores apresentaram e acataram as recomendações sugeridas por este CEP, realizando as alterações proposta tanto no TCLE como na hipótese, desta forma sugiro ao CEP a aprovação do mesmo.

\section{Considerações Finais a critério do CEP:}

Projeto de Pesquisa Aprovado Ad Referendum.

O pesquisador deve atentar que o projeto de pesquisa aprovado por este CEP refere-se ao protocolo submetido para avaliação. Portanto, conforme a Resolução CNS 466/12, o pesquisador é responsável por "desenvolver o projeto conforme delineado", se caso houver alterações nesse projeto, este CEP deverá ser comunicado em emenda via Plataforma Brasil, para nova avaliação.

Cabe ao pesquisador notificar via Plataforma Brasil o relatório final para avaliação. Os Termos de Consentimento Livre e Esclarecidos e/ou outros Termos obrigatórios assinados pelos participantes da pesquisa deverão ser entregues ao CEP. Os relatórios semestrais devem ser notificados quando solicitados no parecer.

Este parecer foi elaborado baseado nos documentos abaixo relacionados:

\begin{tabular}{|c|c|c|c|c|}
\hline Tipo Documento & Arquivo & Postagem & Autor & Situação \\
\hline $\begin{array}{l}\text { Informações Básicas } \\
\text { do Projeto }\end{array}$ & $\begin{array}{l}\text { PB_INFORMAÇÕES_BÁSICAS_DO_P } \\
\text { ROJETO 1267463.pdf }\end{array}$ & $\begin{array}{c}09 / 01 / 2019 \\
08: 34: 49 \\
\end{array}$ & & Aceito \\
\hline Outros & Carta_encaminhamento_Ray.pdf & 09/01/2019 & Armando dos & Aceito \\
\hline
\end{tabular}

Endereço: Rua Silvio Marchione, 3-20

Bairro: Vila Nova Cidade Universitária

UF: SP Municipio: BAURU

CEP: $\quad 17.012-900$

Telefone: (14)3235-8421

Fax: (14)3234-7818

E-mail: cephrac@usp.br 


\section{USP - HOSPITAL DE REABILITAÇÃO DE ANOMALIAS CRANIOFACIAIS}

Continuação do Parecer: 3.112.342

\begin{tabular}{|c|c|c|c|c|}
\hline Outros & Carta_encaminhamento_Ray.pdf & $08: 33: 58$ & Santos Trettene & Aceito \\
\hline $\begin{array}{l}\text { TCLE / Termos de } \\
\text { Assentimento / } \\
\text { Justificativa de } \\
\text { Ausência }\end{array}$ & tcle.docx & $\begin{array}{c}04 / 01 / 2019 \\
11: 55: 23\end{array}$ & $\begin{array}{l}\text { Armando dos Santos } \\
\text { Trettene }\end{array}$ & Aceito \\
\hline Outros & Checklist_Prot_Pesq_109_2018.pdf & $\begin{array}{c}10 / 12 / 2018 \\
17: 37: 15\end{array}$ & $\begin{array}{l}\text { Rafael Mattos de } \\
\text { Deus }\end{array}$ & Aceito \\
\hline Outros & Termo_compromisso.pdf & $\begin{array}{c}10 / 12 / 2018 \\
14: 57: 14\end{array}$ & $\begin{array}{l}\text { Armando dos Santos } \\
\text { Trettene }\end{array}$ & Aceito \\
\hline $\begin{array}{l}\text { Projeto Detalhado / } \\
\text { Brochura } \\
\text { Investigador }\end{array}$ & ProjetoRayanne.pdf & $\begin{array}{c}10 / 12 / 2018 \\
14: 56: 08\end{array}$ & $\begin{array}{l}\text { Armando dos Santos } \\
\text { Trettene }\end{array}$ & Aceito \\
\hline $\begin{array}{l}\text { Declaração de } \\
\text { Pesquisadores }\end{array}$ & Term_Comp_Pesq_Resp.pdf & $\begin{array}{c}07 / 12 / 2018 \\
16: 20: 16\end{array}$ & $\begin{array}{l}\text { Rayanne Meyer } \\
\text { Barduzzi }\end{array}$ & Aceito \\
\hline Outros & Form_Cadastro_HRAC.pdf & $\begin{array}{c}07 / 12 / 2018 \\
16: 18: 57\end{array}$ & $\begin{array}{l}\text { Rayanne Meyer } \\
\text { Barduzzi }\end{array}$ & Aceito \\
\hline Orçamento & Orcamento.pdf & $\begin{array}{c}07 / 12 / 2018 \\
16: 02: 44 \\
\end{array}$ & $\begin{array}{l}\text { Rayanne Meyer } \\
\text { Barduzzi } \\
\end{array}$ & Aceito \\
\hline Folha de Rosto & Folha_Rosto.pdf & $\begin{array}{c}07 / 12 / 2018 \\
16: 01: 47\end{array}$ & $\begin{array}{l}\text { Rayanne Meyer } \\
\text { Barduzzi }\end{array}$ & Aceito \\
\hline
\end{tabular}

\section{Situação do Parecer:}

Aprovado

Necessita Apreciação da CONEP:

Não

BAURU, 14 de Janeiro de 2019

\section{Assinado por:}

Renata Paciello Yamashita

(Coordenador(a)) 